\title{
Heterotrimeric G-proteins in Picea abies and their regulation in response to Heterobasidion annosum s.l. infection
}

Sophie de Vries ${ }^{1,2}$, Miguel Nemesio-Gorriz', Peter B. Blair ${ }^{3}$, Magnus Karlsson', M. Shahid Mukhtar ${ }^{3}$ and Malin Elfstrand ${ }^{1 *}$ (D)

\begin{abstract}
Background: Heterotrimeric G-proteins are important signalling switches, present in all eukaryotic kingdoms. In plants they regulate several developmental functions and play an important role in plant-microbe interactions. The current knowledge on plant G-proteins is mostly based on model angiosperms and little is known about the G-protein repertoire and function in other lineages. In this study we investigate the heterotrimeric G-protein subunit repertoire in Pinaceae, including phylogenetic relationships, radiation and sequence diversity levels in relation to other plant linages. We also investigate functional diversification of the G-protein complex in Picea abies by analysing transcriptional regulation of the G-protein subunits in different tissues and in response to pathogen infection.
\end{abstract}

Results: A full repertoire of G-protein subunits in several conifer species were identified in silico. The full-length P. abies coding regions of one $\mathrm{Ga}-$-, one $\mathrm{G} \beta$ - and four $\mathrm{G} \gamma$-subunits were cloned and sequenced. The phylogenetic analysis of the Gy-subunits showed that PaGG1 clustered with A-type-like subunits, PaGG3 and PaGG4 clustered with C-type-like subunits, while PaGG2 and its orthologs represented a novel conifer-specific putative Gy-subunit type. Gene expression analyses by quantitative PCR of $P$. abies G-protein subunits showed specific up-regulation of the Ga-subunit gene PaGPA1 and the Gy-subunit gene PaGG1 in response to Heterobasidion annosum sensu lato infection.

Conclusions: Conifers possess a full repertoire of G-protein subunits. The differential regulation of PaGPA1 and PaGG1 indicates that the heterotrimeric G-protein complex represents a critical linchpin in Heterobasidion annosum s.l. perception and downstream signaling in $P$. abies.

Keywords: Picea abies, Heterotrimeric G-protein, Gy-subunit, Evolution, Heterobasidion annosum

\section{Background}

Heterotrimeric G-proteins are protein complexes consisting of three subunits $(\alpha-, \beta$ - and $\gamma$-subunit). They are present throughout the plant, animal and fungal kingdoms. Having the ability to recognize and respond to various internal and external stimuli, they regulate many different developmental and environmental responses, such as cell proliferation, cell wall composition, various hormone responses, ion channel regulation, stomatal opening and closure, sugar signaling, pathogen and elicitor responses [1-12].

\footnotetext{
* Correspondence: Malin.Elfstrand@slu.se

'Department of Forest Mycology and Plant Pathology, Uppsala Biocenter,

Swedish University of Agricultural Sciences, Uppsala, Sweden

Full list of author information is available at the end of the article
}

In contrast to the classical model of G-protein activation, known from fungi and animals, many plants show a strong self-activation of the complex, possibly resulting from comparably more fluctuant and dynamic helical protein domain motions $[9,13,14]$. A conformational change in the $G \alpha$-subunit will release the $G \beta \gamma$-dimer and by that activate downstream signalling pathways via either the G $\alpha$-subunit and/or the G $\beta \gamma$-dimer $[15,16]$. Completion of the cycle by inactivation of the heterotrimeric G-protein complex seems to differ not only in plants and animals, but even within the plant kingdom [9].

Downstream signalling of the Go-subunit as well as the G $\beta \gamma$-dimer [3] can act both synergistically and antagonistically [15]. Pandey et al. [17] assessed different models for the downstream signal propagation and found that one 
signalling component can only explain a partial range of the possible reactions, indicating that both parts are involved and needed for the variability in heterotrimeric Gprotein signalling and function. Specificity in signalling is partially determined by the mutually exclusive expression patterns of the Gy-subunits in Arabidopsis thaliana, although e.g. subunit specificity in flowering signalling cannot be explained with this hypothesis [18]. Additionally, functional diversity is hypothesised to be determined by the number and sequence variation of the complex components, e.g. in animals and fungi a wide variety of $\mathrm{G} \alpha-$ subunits can account for functional diversity $[19,20]$.

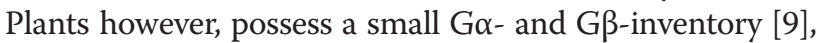
implying that functional diversity of the plant heterotrimeric G-protein complex is dependent on the number and variation of $G \gamma$-subunits [21].

Accordingly, Gy-subunits in plants form a small gene family with up to three members that usually show strong sequence diversification [9, 22]. Phylogenetically, plant $\mathrm{G} \gamma$-subunit sequences can be classified into three subtypes [22], based on the sequence, the length of their C-terminal region and the motifs therein. A-type-like $\mathrm{G} \gamma$-subunits are short proteins containing a C-terminal CAAX motif similar to fungal and animal $\mathrm{G} \gamma$-subunits [22], and are the only Gy-subunit type identified in green algae [23]. The B-types are also short proteins, but have diverged in monocots and dicots possessing the Cterminal motifs KGSDFS and SRXXKRWI, respectively [22]. Trusov and colleagues [22] found no B-type-like sequence in gymnosperms, prompting them to suggest that the B-type diverged from the A-type after the split of gymnosperms and angiosperms between $300 \mathrm{My}$ ago (mya) to 150 mya (based on Pires and Dolan [24]), with a secondary loss in the Brassicaceae. The C-types are longer proteins with a cysteine-rich $\mathrm{C}$-terminus, but the length varies considerably in this group [22]. Interestingly, the moss Physcomitrella patens is predicted to have a Gy-subunit not represented in spermatophyta [22], suggesting that additional Gy-subunit types may be discovered.

In line with their important functional roles as switches between signal perception and transduction, transcriptional regulation of heterotrimeric G-proteins towards environmental and developmental cues are studied in detail in angiosperms [21, 25-28], and add further support to sequence variation as a key in the broad variety of signalling functions. Analyses of gene expression patterns in A. thaliana reveal omnipresent $A G B 1$ (GB) expression that coincide with the Gy-subunit AGG1- and AGG2-expression, although the latter two are expressed tissue dependent and mostly mutually exclusive [21].

Lately, G-protein signalling is established as a major component in pathogen responses in both monocots and dicots. Suharsono et al. [29] showed that in rice, the
$\mathrm{G} \alpha$-subunit is an important intermediary of defence responses activated by Magnaporthe grisea elicitors, which suggest a role of the $\mathrm{G} \alpha$-subunit in effector triggered immunity (ETI). However, several subunits of the heterotrimeric G-protein complex respond to microbe associated molecular patterns (MAMPs) [12, 30, 31], indicating a role in pattern triggered-immunity (PTI). In A. thaliana, activation of PTI require functional G $\beta$ - and certain $\mathrm{G} \gamma$ subunits, while the only C-type $\mathrm{G} \gamma$-subunit, $A G G 3$, does not seem to be involved in PTI [30]. This suggests functional differentiation in the G-protein subunit repertoire in A. thaliana, as well as a species specific usage of the heterotrimeric G-protein repertoire. In line with this, the heterotrimeric G-protein components are required for host and non-host resistance in A. thaliana, with the exception of AGG3 [32]. Lee and colleagues [32] also showed that all involved subunits are significantly higher expressed during biotic stress.

Despite being such an important signalling switch, research on heterotrimeric G-proteins is focussed on annual plants. In plants with perennial life styles, such as trees, abiotic and biotic stress are enduring threats that the plants constantly must react to. A quick and functionally specific switch may thus be crucial for the plants longevity. Also, information on the G-protein subunit repertoire in gymnosperms would add important information on heterotrimeric G-protein evolution. Yet, despite their evolutionary history and their ecological and economic importance, our knowledge on heterotrimeric G-proteins in gymnosperms is very superficial. Mostly, Go-, G $\beta$ - and Gy-subunit gene sequences in Pinaceae are predicted based on expressed sequence tag (EST) sequences $[9,22]$. This data suggest that Pinaceae, like most

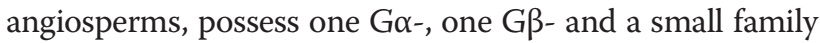
of Gy-subunit genes. However, with the aid of the newly published first genome from the conifers, the Norway spruce [Picea abies (L.) Karst.] genome [33], additional information may be gained.

In Europe the economically most important pathogen on Pinaceae is the basidiomycete fungus Heterobasidion annosum (Fr.) Bref. sensu lato (s.l.). It is a necrotrophic pathogen specialized on conifers and its spread parallels that of its host (reviewed by Korhonen and Stenlid, [34]). Independent of the co-evolutionary history, the defense responses triggered by $H$. annosum s.l. in $P$. abies are suggested to be non-specific [35-37], resembling PTI. In Europe, two Heterobasidion species are known to infect $P$. abies, $H$. annosum sensu stricto (s.s) and $H$. parviporum [38] causing stem and root rot in the infected tree, devaluing the timber and increasing the risk of wind-throw [34].

In this study we used the newly available Norway spruce genome in combination with EST databases to elucidate the heterotrimeric G-protein complex in Pinaceae 
for evolutionary analyses. Our phylogenies, including more Pinaceae sequences, are coherent with previous studies on plant evolution, with regards to $G \alpha-$ and $G \beta-$ subunits. The phylogeny of $\mathrm{G} \gamma$-subunits indicate lineagespecific radiation. We identify a dicot-specific A-type, as well as a novel gymnosperm type not represented in more basal or higher lineages. Sequence diversifications indicate subfunctionalization of the different $\mathrm{G} \gamma$-subunits in the Pinaceae, which is supported by tissue specific expression in Norway spruce. We observe changes in the expression patterns of the heterotrimeric G-protein subunit genes in response to wounding, methyl jasmonate (MeJA), abscisic acid (ABA), a saprotrophic fungus and the necrotrophic pathogen $H$. annosum s.l. This consistent with a patterntriggered response that is either independent or upstream of the hormone signalling pathways. To the best of our knowledge we present here the first report on heterotrimeric G-protein signalling in perennial species towards biotic stresses.

\section{Results \\ Conifers encode and express a full repertoire of heterotrimeric G-protein subunits}

Previous studies $[9,22]$ had already reported some sequences of the Pinaceae heterotrimeric G-protein complex, based on EST sequences. We identified one $\mathrm{G} \alpha-$, one $\mathrm{G} \beta$ and four $\mathrm{G} \gamma$-subunit-like gene sequences in the P. abies genome [33]. The same number was identified in Picea sitchensis, while one G $\beta$ - and only three Gy-subunit-like sequences were found in Picea glauca and Pinus taeda. The G $\alpha$-subunit-like sequences for these two species were reported previously by Urano et al. [9]. In addition, we also identified Go-subunit-like sequences in additional Pinus species. All sequences used in the current study are listed in Additional file 1. While we found gene models for all subunits in the $P$. abies genome assembly, only PaGG1 had a high confidence gene model that covered the whole sequence. This was not surprising, due to the large genome size, long introns, and high content of repetitive regions, which limited the $P$. abies assembly [33]. We confirmed the in silico identified $\mathrm{G} \alpha-$, $\mathrm{G} \beta$ - and $\mathrm{G} \gamma$-like genes from $P$. abies by cloning and sequencing the full-length coding sequences from cDNA libraries [KM197161 (PaGPA1) and KC825350.1-KC825354.1 (PaHGB1 - PaGG4)]. In our subsequent studies we used the sequences determined from $P$. abies cDNA.

In general, the G-protein repertoire in Pinaceae was similar in numbers between the investigated species. The lengths of the predicted G-protein-like subunit amino acid sequences were conserved between species in Pinaceae, with the exception of the putative P. taeda GG3 that was 38 amino acids shorter than the orthologous PaGG3 (Fig. 1). The predicted molecular weights of the $G \alpha$-subunit-like PaGPA1 and the G $\beta$-subunit-like
PaHGB1 proteins from P. abies were 45.4 and $41.4 \mathrm{kDa}$, respectively, while the molecular weights of the $\mathrm{G} \gamma$ subunit-like proteins were predicted to be equal to, or lower than $23.4 \mathrm{kDa}$ (Table 1).

The predicted Gy-subunits separated into two short $($ PaGG1 $=336$ amino acids and PaGG2 $=318$ amino acids) and two long (PaGG3 = 513 amino acids and PaGG4 = 624 amino acids) proteins (Table 1). The Gy-like subunits were divided into four different types, based on the highly variable $\mathrm{N}$ - and $\mathrm{C}$-terminal parts. We identified four conserved N-terminal motifs for the different $\mathrm{G} \gamma$ subunit-like proteins in Pinaceae: GG1 - MEEET (Picea)/ MEQET (Pinus), GG2 - MQGT (Picea/Pinus), GG3 MINKS (Picea)/ MISKS (Pinus) and GG4 - MIK (Picea) (Fig. 1). Further, they showed specific C-termini (Fig. 1): PaGG1 contained a CAAX motif (CWII) that classified PaGG1 and its orthologs as an A-type Gy-subunit; PaGG3 and PaGG4 had long C-termini with high cysteine contents of $29 \%$ (PaGG3) and $30 \%$ (PaGG4), representing Ctype Gy-subunits; while the short subunit PaGG2 and its orthologs contained a novel motif (SRGCGCCL), previously not shown to be present in monocots or dicots [22]. PaGG1 but not PaGG2 show a complete G-protein $\gamma$ subunit-like (GGL)-domain [39] (Additional file 2).

\section{Conifers contain a novel $\mathrm{G} \gamma$-subunit type}

To better understand how the heterotrimeric G-protein complex has evolved we conducted phylogenetic analyses of the components. Our phylogenetic analysis confirmed that the $G \alpha$-subunit-like and $G \beta$-subunit-like sequences mainly follow previously published plant phylogenies [24, 40, 41] (Additional files 3, 4 and 5).

The resulting phylogenetic tree for $\mathrm{G} \gamma$-subunit-like sequences demonstrated type-dependent, rather than plant evolution dictated topology (Fig. 2). We obtained clusters representing A-type-like, B-type-like and Ctype-like proteins, respectively (Fig. 2, Additional file 6). PaGG1 and its orthologs in Pinaceae clustered with the angiosperm A-type-like sequences (Fig. 2). In agreement with the unique C-terminal ending, PaGG2 and its conifer homologs formed a separate clade, related with the A-type-like cluster (Fig. 2). This is in accordance with the higher amino acid similarity between PaGG1 and PaGG2 (56.5 \%), compared to the overall mean similarity between all P. abies Gy-subunit-like types (29.9 \%). The C-type-like cluster was split into two groups: one containing dicot and the other conifer proteins, including PaGG3 and PaGG4 (Fig. 2).

\section{Yeast two hybrid assay with conifer G-protein subunits}

For heterotrimeric G-proteins to be functional, the $\mathrm{G \alpha}$-, $\mathrm{G} \beta$ - and $\mathrm{G} \gamma$-subunits must physically interact with each other as it has been shown in other model organisms $[12,42]$. To analyse this protein-protein interactions 


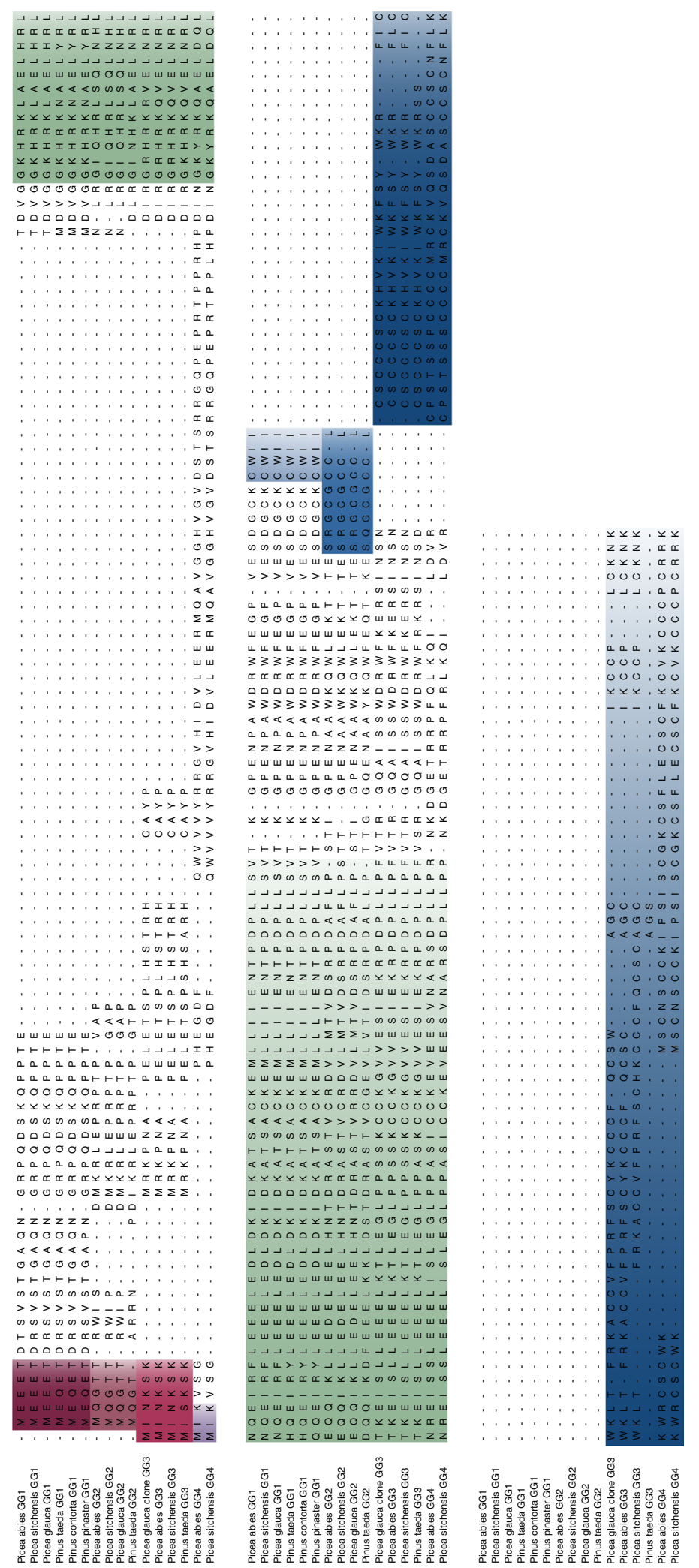

Fig. 1 (See legend on next page.) 
(See figure on previous page.)

Fig. 1 Alignment of the isolated P. abies Gy-subunits. Alignment of the predicted amino acid sequences of PaGG1, PaGG2, PaGG3 and PaGG4. The alignment was done using CLUSTALW in MEGA5.0. The conserved N-terminal motifs of Pinaceae GG1, GG2, GG3 and GG4 are highlighted (in purple). The conserved region in Gy-subunits found in the plant kingdom is highlighted in green. The type-specific C-termini are highlighted in blue

among the members of G-proteins in Norway spruce, we performed a comprehensive yeast two-hybrid assay. All subunits were fused with both a GAL4 activator domain (AD) and a GAL4 binding domain (DB) individually. These constructs were subsequently transformed into haploid yeast strains and mated in a simple crosswise matrix (Fig. 3). Protein-protein interactions were scored based on yeast growth on selection media but no growth on the autoactivation media. As expected PaGPA1-AD interacted with PaHGB1-DB (Fig. 3). Also, PaHGB1-AD showed interaction with the Gy-subunits PaGG1-DB, PaGG3-DB and PaGG4-DB, but not with PaGG2-DB (Fig. 3). Instead, PaGG2-AD interacted with PaGG1-DB but not with itself, PaGG3-DB or PaGG4-DB.

As a limited interaction between $\mathrm{G} \gamma$ - and $\mathrm{G} \alpha$-subunits have been reported [42] in the absence of the G $\beta$-subunit in mammalian systems [43-45] we also tested the interaction between PaGPA1 and the identified Gy-subunits. Indeed, the PaGPA1-AD interacted with PaGG1-, PaGG2, PaGG3- and PaGG4-DB (Fig. 3).

\section{Different levels of sequence diversification indicate subfunctionalization of $\mathrm{G} \gamma$-subunits}

Gy-subunits show a low overall conservation in the plant kingdom, which suggests that sequence variation may result in functional divergence. We therefore assessed if $\mathrm{G} \gamma$-subunits evolve under different evolutionary constraints, by performing pairwise comparisons of amino acid conservation in the A- and C-type Gy-subunit clusters in Pinaceae, Brassicaceae and Fabaceae. Brassicaceae and Fabaceae were chosen as valid angiosperm comparisons as their divergence times (125 mya [46]) are similar to the divergence time between the genera Picea and Pinus (145 mya [40, 41]). For comparison, we also conducted this analysis for the
G $\alpha$-subunit in the same taxa. The lowest sequence variation was detected for the Go-subunit (Fig. 4a). The highest sequence variation was found in angiosperm Ctype-like Gy-subunits (Fig. 4b). Sequence variation was significantly $(P \leq 0.05)$ lower for all conifer $\mathrm{G} \gamma$-subunitlike and the $\mathrm{G} \alpha$-subunit-like sequences, compared with their angiosperm equivalents (Fig. 4).

\section{Differential Gy-subunit gene expression indicate subfunc- tionalization in $P$. abies}

The observed differences in amino acid conservation between the Gy-subunit types may suggest sub- or neofunctionalization. To test this, we studied gene expression of PaGPA1, PaHGB1, PaGG1, PaGG2 and PaGG3 in cotyledons and roots of $P$. abies seedlings at 4, 24 and $72 \mathrm{~h}$ after transfer to fresh medium (Fig. 5). Roots showed a higher expression $(P \leq 0.05)$ of $P a G P A 1$, PaHGB1, PaGG1 and PaGG2 compared to cotyledons over time. PaGG3 showed stable expression levels over time and tissues, although with decreased levels in cotyledons after $72 \mathrm{~h}$.

After having established basal expression levels, we investigated the effect of abiotic and biotic stress on G-protein subunit gene expression. Expression of PaGPA1, PaHGB1, PaGG1, PaGG2 and PaGG3 was analysed in cotelydons and roots at 4,24 and $72 \mathrm{~h}$ post infection (hpi) with $H$. annosum s.s. conidiospores. In a separate experiment, seedlings were treated with the defense signalling hormones abscisic acid (ABA) and methyl jasmonate (MeJA), as well as a wounding treatment. Expression levels of PaGPA1, PaHGB1, PaGG1 and $P a G G 3$ were significantly $(P \leq 0.05)$ induced in $P$. abies roots after 72 hpi with $H$. annosum s. s. (Table 2). The induction of PaGPA1 was detectable already at 24 $\mathrm{hpi}$, and reached a five-fold induction at $72 \mathrm{hpi}$.

Table 1 Molecular data of the predicted P. abies G-protein subunits

\begin{tabular}{|c|c|c|c|c|c|c|c|c|}
\hline \multirow[b]{2}{*}{ Gene } & \multirow{2}{*}{$\begin{array}{l}\text { Predicted } \\
\text { transcript }\end{array}$} & \multirow{2}{*}{$\begin{array}{l}\text { Gene } \\
\text { model }\end{array}$} & \multirow[b]{2}{*}{ NCBI accession } & \multirow[b]{2}{*}{ ORF (bp) } & \multirow{2}{*}{$\begin{array}{l}\text { Predicted } \\
\mathrm{MW}(\mathrm{kDa})\end{array}$} & \multicolumn{2}{|c|}{ Amino acid motifs } & \multirow[b]{2}{*}{ Type $^{\mathrm{a}}$} \\
\hline & & & & & & $\overline{N \text {-terminal }}$ & C-terminal $^{a}$ & \\
\hline \multirow[t]{2}{*}{ PaGPA1 } & comp91545_c0_seq2 & MA_95177 & KM197161.1 & 1016 & 45.4 & - & - & - \\
\hline & /comp92545_c1_seq1 & /MA_9999470g0010 & & & & & & \\
\hline PaHGB1 & comp75963_c0_seq1 & MA_10429560g0010 & KC825350.1 & 1134 & 41.4 & - & - & - \\
\hline PaGG1 & comp86733_c0_seq1 & MA_87554g0010/MA_183273g0020 & KC825351.1 & 336 & 12.5 & MEEET & CaaX & A \\
\hline PaGG2 & comp85221_c0_seq1 & MA_202946g0010 & KC825352.1 & 318 & 12.0 & MQGT & SRGCGCCL & A-like \\
\hline PaGG3 & comp79582_c0_seq1 & MA_173928g0010 & KC825353.1 & 513 & 19.8 & MINKS & C-rich & C \\
\hline PaGG4 & comp42525_c0_seq1 & MA_66599g0010 & KC825354.1 & 624 & 23.4 & MIK & C-rich & $C$ \\
\hline
\end{tabular}

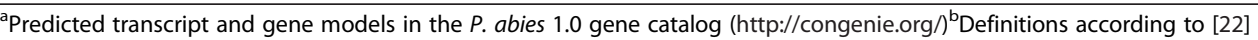




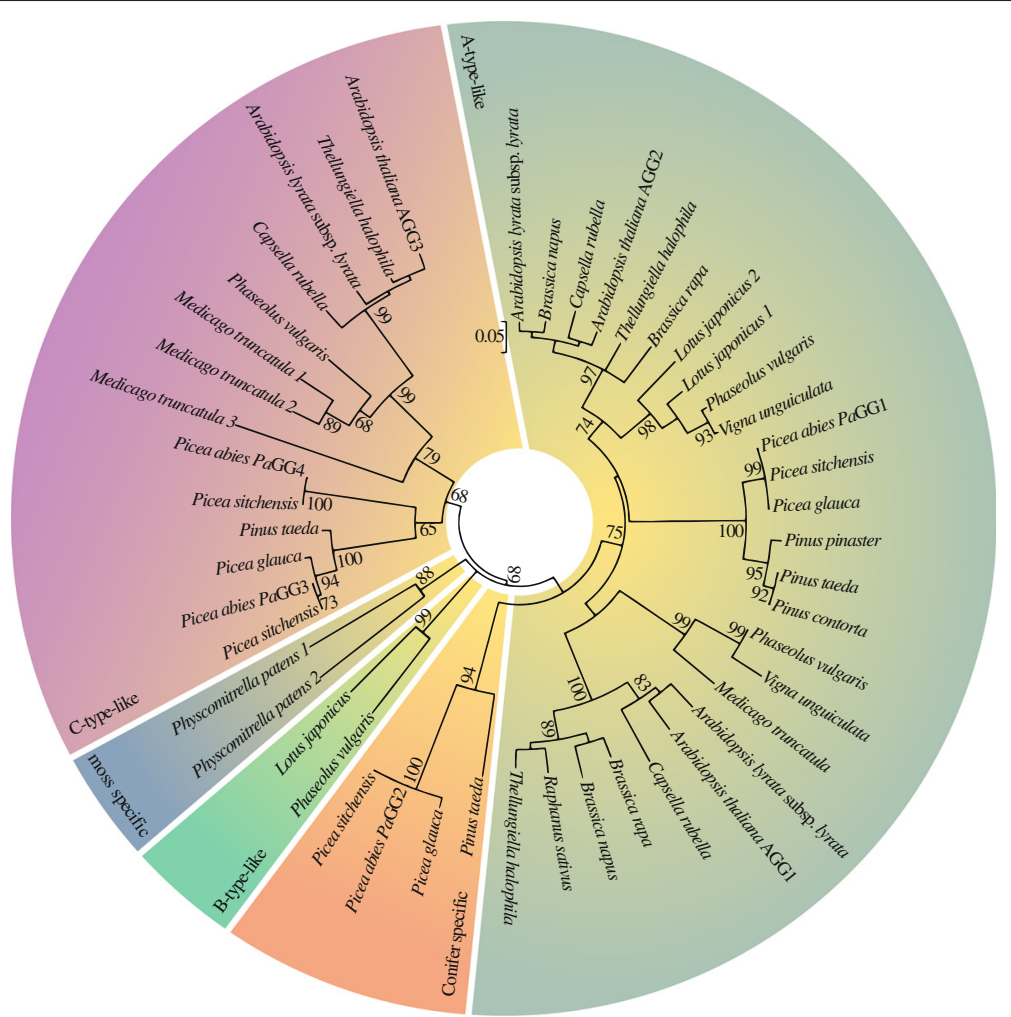

Fig. 2 Evolutionary relationships of the Gy-subunits in the plant kingdom. Neighbor-Joining tree of the Gy- subunit-like sequences of Pinaceae, Fabaceae, Brassicaceae and the moss Physcomitrella patens; A-type-like sequences containing a CAAX-box motif are highlighted in olive, B-type-like sequences are highlighted in green, C-type-like sequences having long cysteine-rich C-termini are highlighted in pink, conifer specific short sequences are highlighted in orange and moss sequences in blue. Bootstrap support over 65 is associated with lineages

Expression of PaGG3 was induced in cotyledons, as well as in roots. Hormonal treatments or wounding did not induce any changes in expression of any gene (Additional file 7).

To further investigate the response of PaGPA1, PaGG1, PaGG2 and PaGG3 to H. annosum s.l., their expression was analysed in bark of 4-year old P. abies plants subjected to wounding or inoculation with $H$. parviporum or the saprotrophic fungus Phlebiopsis gigantea, unable to colonize $P$. abies bark tissue [47]. Expression levels were quantified $72 \mathrm{hpi} /$ wounding directly at the inoculation/wounding site and at a distal

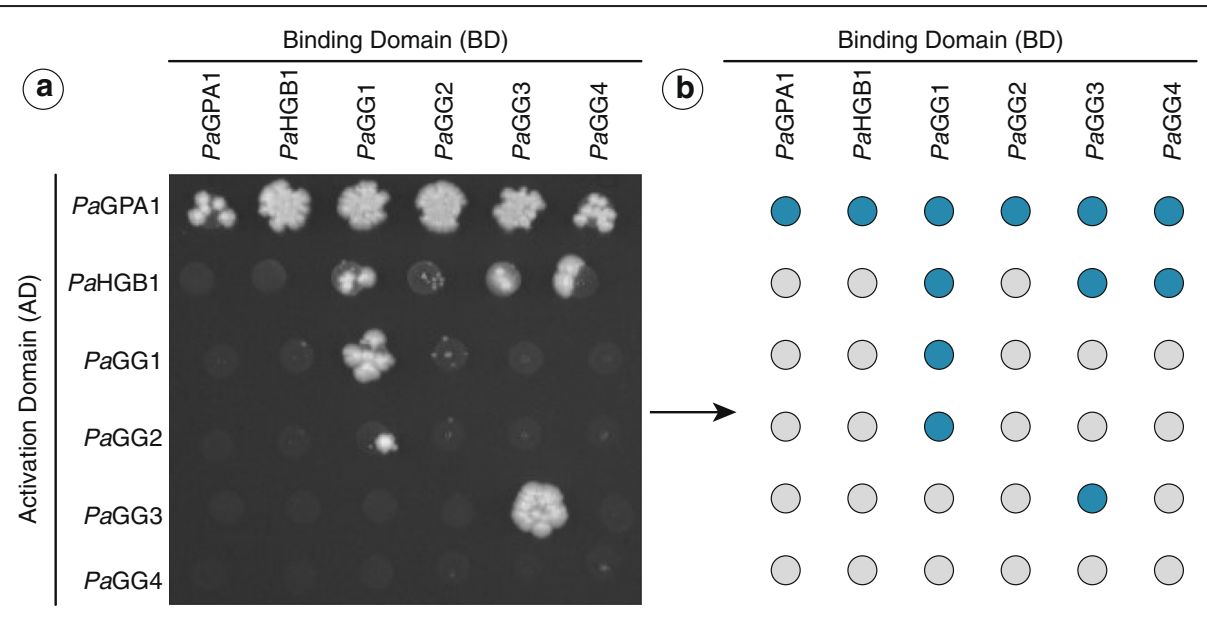

Fig. 3 Interactions of P. abies G-protein subunits. Yeast-2-Hybrid screening of direct interactions of the identified P. abies G-protein subunits on -LTH agar plates (a). The experimental matrix of G-Protein AD/DB mates: blue indicates interaction on -LTH agar plates (b) 


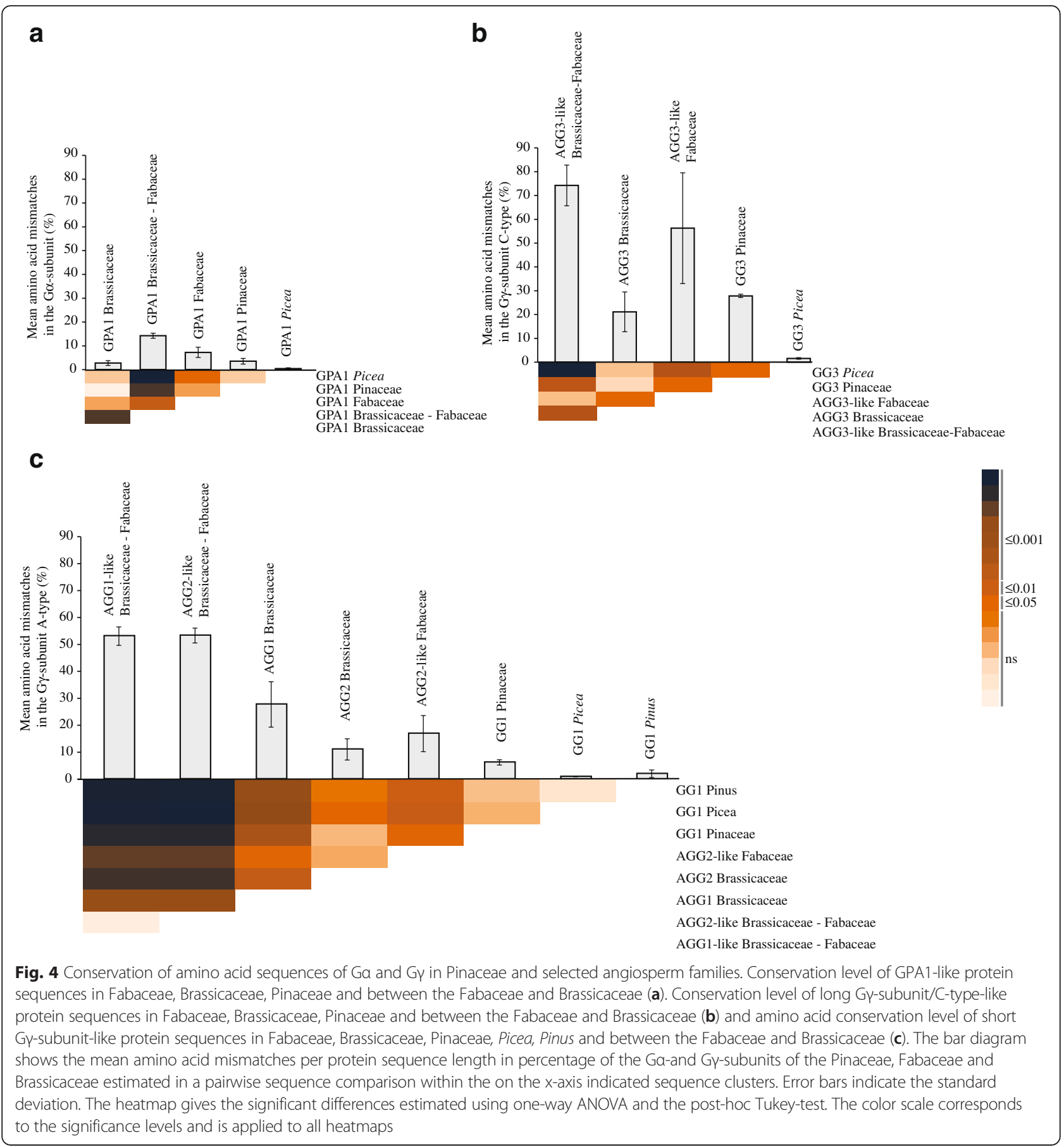

position, $2 \mathrm{~cm}$ away from the inoculation site. PaGG2 expression in bark was below the detection limit of the assay. None of the other subunit genes were differentially expressed in response to either fungal inoculum in comparison to wounding at the local site (Fig. 6a). However, at the distal location, expression of PaGPA1 and PaGG1 were induced by $H$. parviporum infection, but not by $P$. gigantea, when compared to the wounding control (Fig. 6b).

\section{Discussion}

Conifers possess a unique short G $\gamma$-subunit type not present in other land plants

In this study we set out to investigate presence and functionality of heterotrimeric G-proteins in woody plants. We focus on the conifer P. abies and several of its close relatives. We identified and verified the presence of one $\mathrm{G} \alpha-$, one $\mathrm{G} \beta$ - and four different $\mathrm{G} \gamma$-subunit genes in $P$. 
a

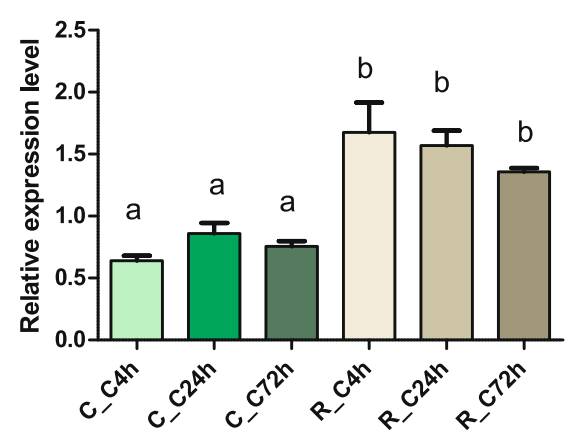

C

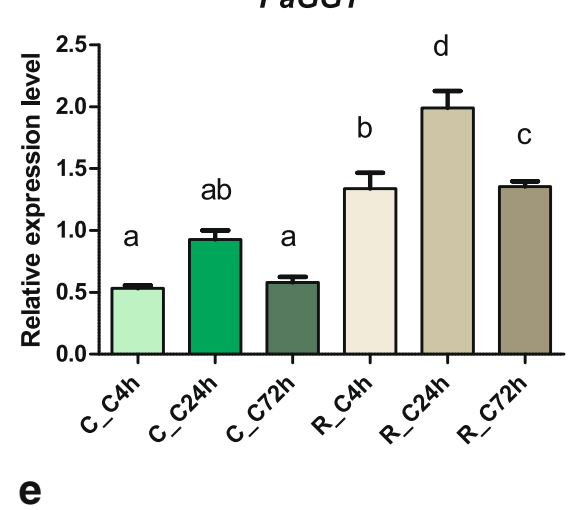

PaGG3

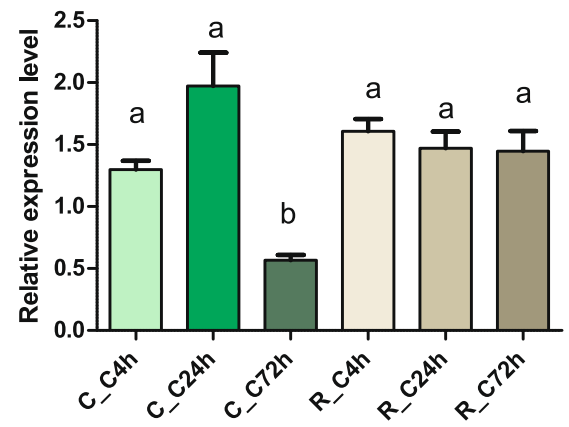

b

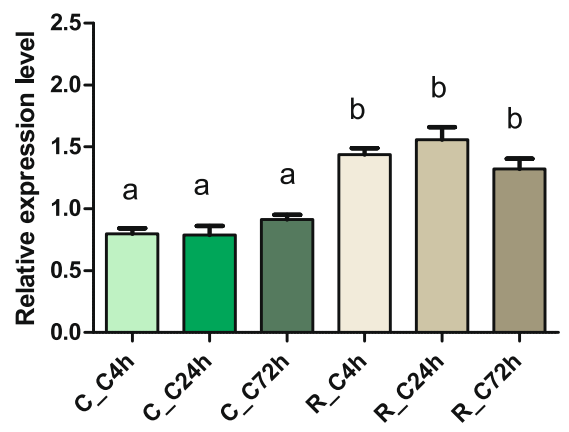

d

PaGG2

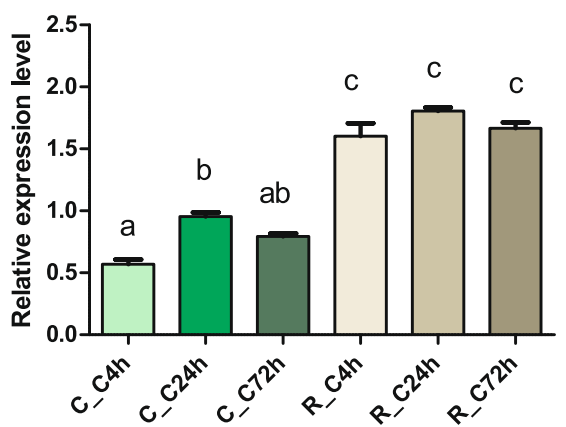

Fig. 5 Tissue specificity of G-protein subunits in P. abies. The relative expression values in cotyledons and roots of P.abies seedlings of PaGPA1 (a); PaHGB1 (b); PaGG1 (c); PaGG2 (d) and PaGG3 (e) The relative expression in cotelydons (C) and roots (R) at 4-, 24- and 72 relative to time point t $0=0 \mathrm{~h}$ is indicated is shown. Numbers in the sample code represent the time points at which the tissues were collected. The letters on the bars indicate different statistical groups and the standard deviation is given by error bars $(\mathrm{N}=3)$

abies and found the orthologous genes in other conifers. Our survey identified an additional $\mathrm{G} \gamma$-subunit gene in $P$. abies and $P$. sitchensis, not present in P. glauca and P. taeda. The observations for P. taeda and P. glauca are in accordance with the three Gy-subunit genes previously reported from Pinaceae [9], and could suggest that the Picea lineage gained a fourth Gy-subunit gene that was later lost in P. glauca. However, as the conifer sequences, except $P$. abies, are retrieved from EST databases, we cannot exclude the existance of additional genes.
The four different predicted $\mathrm{G} \gamma$-subunit-like protein sequences from $P$. abies can be divided into short and long variants. The modular structures classify PaGG1 as an A-type Gy-subunit, and PaGG3 and PaGG4 as members of the C-type-like $\mathrm{G} \gamma$-subunit group, according to the description by Trusov et al. [22]. We found this to be in complete agreement with their phylogenetic placements in our current study. The phylogeny indicates that GG3 and GG4 are recent duplicates that arose during conifer evolution. Based on our data, the most parsimonious hypothesis indicates the duplication event took 
Table 2 Transcriptional regulation of G-protein subunits seedling roots in response to $H$. annosum s.s

\begin{tabular}{llllll}
\hline & \multicolumn{2}{l}{ Cotelydons } & & Roots \\
\cline { 2 - 3 } \cline { 6 - 7 } & $24 \mathrm{hpi}^{\mathrm{a}}$ & $72 \mathrm{hpi}^{\mathrm{a}}$ & & $24 \mathrm{hpi}^{\mathrm{a}}$ & $72 \mathrm{hpi}^{\mathrm{a}}$ \\
\hline PaGPA1 & $1.2 \pm 0.0$ & $1.4 \pm 0.1$ & & $2.9 \pm 0.8^{* *}$ & $4.9 \pm 3.0^{*}$ \\
PaHGB1 & $1.3 \pm 0.0$ & $1.0 \pm 0.1$ & & $1.7 \pm 0.1$ & $2.5 \pm 1.5^{*}$ \\
PaGG1 & $1.2 \pm 0.1$ & $0.9 \pm 0.1$ & & $1.5 \pm 0.0$ & $2.8 \pm 1.3^{*}$ \\
PaGG2 & $1.1 \pm 0.1$ & $0.9 \pm 0.1$ & & $1.2 \pm 0.1$ & $2.2 \pm 0.9$ \\
PaGG3 & $1.1 \pm 0.1$ & $2.4 \pm 0.5^{* *}$ & & $1.9 \pm 0.0$ & $2.7 \pm 0.9^{*}$ \\
\hline
\end{tabular}

${ }^{a}$ Relative expression values of PaGG1, PaGG2, PaGG3, PaHGB1 and PaGPA1 in cotelydons and roots of $P$. abies at 24 and $72 \mathrm{~h}$ post inoculation (hpi) with Heterobasidion annosum s. s. conidia suspension relative to time point t $0=0 \mathrm{~h}$ $(\mathrm{N}=3)$.

* Indicate significantly induced expression compared to the control at $P<0.05$ and $>0.01 * *$ Indicate significantly induced expression compared to the control at $P<0.01$ and $>0.001$

place after the split of the genera Picea and Pinus, with GG3 being the ancestral sequence. The sequence of PaGG2 and its coniferous orthologs contain a novel Cterminal motif matching neither A- or C-type-like sequences, nor the monocot or dicot specific B-type

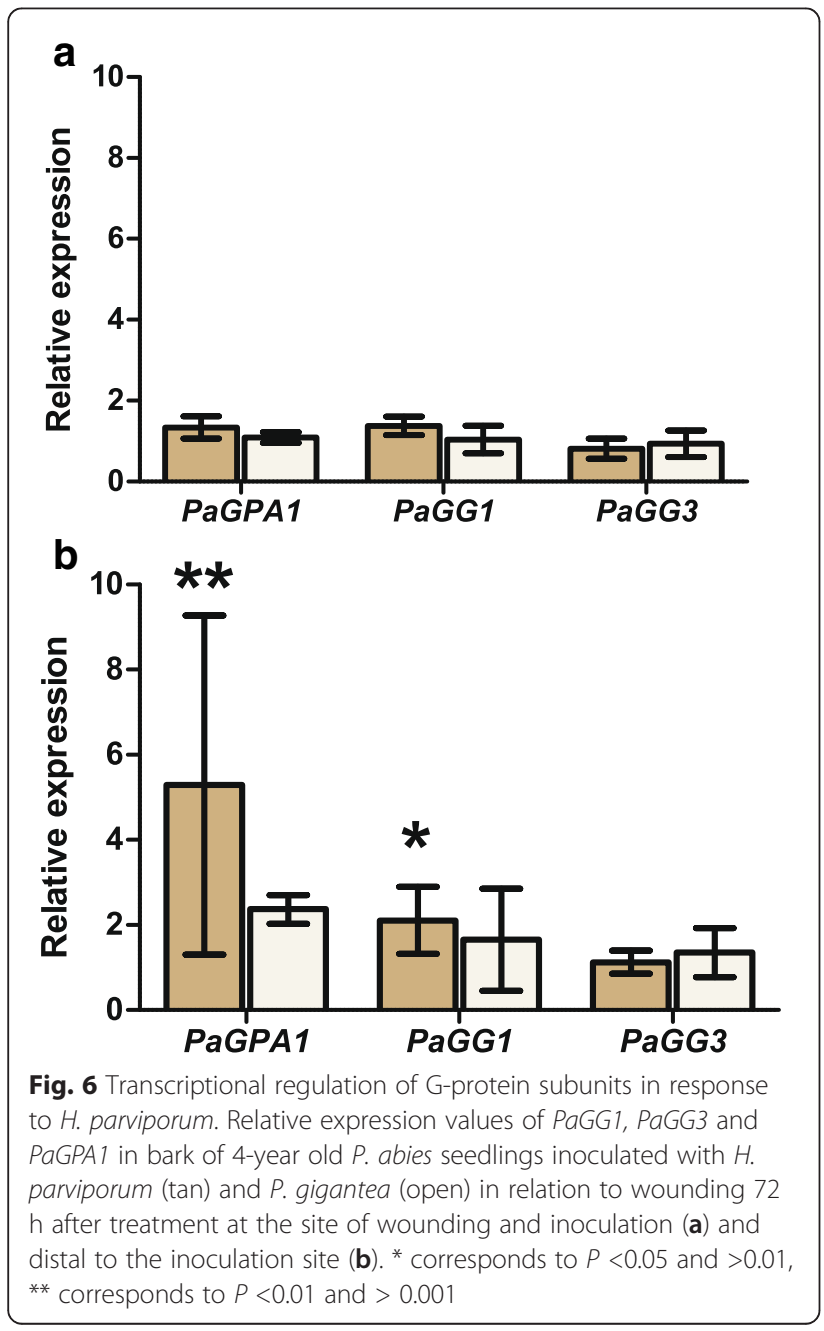

sequences. The phylogenetic analysis, together with the observed high similarity between PaGG2 and PaGG1, suggest that PaGG2 and its orthologs have diverged from the A-type-like clade. Thus, PaGG2 and its orthologs may represent a novel, conifer-specific $\mathrm{G} \gamma$-subunit type.

\section{Conifer Gy-subunits interact differently with PaHGB1 and PaGPA1}

As expected with a single $G \alpha$ - and $G \beta$ gene PaGPA1 interacted with PaHGB1 in the yeast-2-hybrid screen. The smaller $\mathrm{G} \gamma$-subunits are essentially buried in the $\mathrm{G} \beta$-subunit, except for the N-terminus of the $\mathrm{G} \gamma$ subunit, [42] forming the G $\beta \gamma$-dimer [15]; we found that PaHGB1 interacts with the Gy-subunits PaGG1, PaGG3 and PaGG4 but not with the novel, conifer specific, $G \gamma$ subunit PaGG2; raising a question about PaGG2's functionality. An inspection of the predicted secondary structure of the PaGG2 protein indicates that PaGG2 forms only one $\alpha$-helix instead of two in the GGL-domain [39]. Such an incomplete GGL domain may interact only weakly with the G $\beta$-subunit.

In accordance with previous reports from mammalian systems we found that PaGPA1 also interacted with each one of the P. abies Gy-subunits, including PaGG2. The interactions between mammalian $\mathrm{G} \gamma$ - and $\mathrm{G} \alpha$-subunits in the absence of the G $\beta$-subunit [42-45] have been suggested to depend on the $\mathrm{N}$-terminal region of $\mathrm{G} \gamma$ proteins [45] protruding from the $G \beta \gamma$-dimer, and to have a potential effect on the activation of $\mathrm{G} \alpha$ subunits [48] however the corresponding results have not yet been reported from plants.

\section{Sequence divergence of the heterotrimeric G-protein complex differs between conifers and angiosperms}

In most plant species the $G \gamma$-subunits are the only part the heterotrimeric G-protein complex that have more than one gene family member [9]. In addition, they are highly variable in sequence and the differences in their transcriptional responses are suggested as critical factors in the broad role of G-protein responses [18, 21, 22, 32]. High sequence divergence and specific gene regulation are indicators for sub- and/or neofunctionalization. The Gy-subunit sequences demonstrate a much stronger sequence diversification, especially among C-type-like sequences ( $\leq 75 \%$ amino acid substitutions) compared to the $G \alpha$-subunits ( $\leq 15 \%$ amino acid substitutions). This result is aligned with the variable number of Gy-subunit genes in most plants [9]. Interestingly, we also show that G-protein subunit sequences in Pinaceae are more conserved compared to their dicot counterparts, irrespectively of subunit type. Knowing that gymnosperms generally present a slower evolution than angiosperms, probably due to their long life-spans and large effective 
population sizes [49], we attribute this observation to the coniferous lifestyle. Such differences in sequence divergence may indicate functional divergence, which is demonstrated by the significant difference between the Brassicaceae AGG1 and AGG2 orthologue groups that have mutually exclusive gene expression patterns [21].

\section{The conifer G-protein complex shows specific regulation}

The different levels of sequence conservation prompted us to study gene expression of the heterotrimeric Gprotein complex in $P$. abies within different tissues. In contrast to the green algae Chara braunii [23], we found a ubiquitous but tissue-differentiated expression pattern of all subunits. In this respect, the expression pattern is more similar to what is seen in angiosperms compared to more basal lineages, resembling those reported for the putative orthologs in Brassica napus and A. thaliana [3, 21, 26, 27]. The PaHGB1 expression also coincides with expression of PaGG1 and PaGG2 as expected for interacting $\mathrm{G} \beta$ - and $\mathrm{G} \gamma$-subunits, despite that we could not demonstrate an interaction between PaHGB1 and PaGG2 in the yeast-two-hybrid assay. Interestingly, the constitutive expression of PaGG3 in P. abies seedlings is in accordance with the constitutive expression of $A G G 3$ in A. thaliana seedlings [3].

\section{H. annosum s.l. triggers G-protein expression in a MAMP- responsive manner}

Our interest in functional divergence of the heterotrimeric G-protein responses in pathogen defense signalling led us to study expression patterns of the P. abies G-protein subunit genes within different tissues and under different pathogen associated treatments. In the $P$. abies- $H$. annosum s.l. pathosystem, wounding and pathogen inoculation show a qualitatively similar response, although the response to the pathogen has a higher amplitude and duration $[35,36$, 47]. This indicates that the defence responses against $H$. annosum s.l. are MAMP-triggered, but similar to a DAMPtriggered [50] wound response [35-37, 47]. The response also involves hormone triggered defense pathways as JA mediated resistance $[35,47]$. Interestingly, the $P$. abies Gprotein subunits PaGPA1, PaHGB1, PaGG3 and PaGG1 in seedling roots respond to $H$. annosum s.s. treatment, but not to wounding of the seedling. The response in bark of four-year old seedlings was similar, but do not differ between treatments of $H$. annosum s. $l$. and P. gigantea, a non-pathogenic fungus [47] at the treatment site, indicating MAMP-based signalling cues irrespective of seedling age. The differential regulation of PaGG1 and PaGG2 in roots of young seedlings suggests functional differentiation between them, in accordance with the different levels of sequence conservation between orthologs.

We also observed that wounding responses and the response to the saprotroph $P$. gigantea in inoculated bark on branches of four-year old seedlings will weaken with distance [47], while the response to $H$. parviporum persists. We suggest that this phenomenon occurs because of the colonization of the living bark by the pathogen and the continuous release of MAMPs. Consequently, PaGPA1 and PaGG1 are significantly induced at the distal location only in $H$. parviporum treatments. The observation that the response to $H$. parviporum and $P$. gigantea differ agrees with results from Schwacke and Hager's [51], showing that the amplitude of the P. abies response increase with elicitors from $H$. annosum s. $l$. compared to elicitors from ectomycorrhizal fungi. Based on pharmacological studies the responses observed by Schwacke and Hager [51] have been suggested to be mediated by either an (auto) phosphorylation of a membrane-bound receptor kinase prior to the activation of a G-protein or (and) immediately downstream of the activated G-protein [52]. These observations are in agreement with our results and our suggestion of heterotrimeric G-proteins acting upstream of JA-signaling,

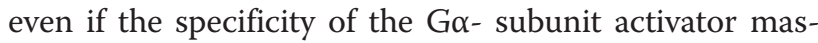
toparan, used in [52], has been questioned [53], it is an interesting observation and we think that it merits further studies the role of PaGPA1 and its orthologs in MAMP perception in Pinaceae.

\section{Conclusions}

P. abies possess a full repertoire of G-protein subunits, including a novel conifer-specific short Gy-subunit type ( $P a G G 2$ and its orthologs). However, the functionality of PaGG2 is questionable, given that the protein appears not to interact with $\mathrm{PaHGB1}$. Sequence divergence suggests relaxed evolution of the $\mathrm{G} \gamma$-subunits compared to the $\mathrm{G} \alpha$ subunits, a pattern typical for duplicated genes. Different evolutionary constraints between the Gy-subunits are concomitant with the different expressional responses towards unchallenged and challenged situtations. This indicates subfunctionalization of the paralogous $G \gamma$-repertoire. Further, differential regulation of PaGPA1 and PaGG1 in response to $H$. annosum s.l. infection indicates that the heterotrimeric G-protein complex represents a critical linchpin in pathogen-perception and downstream signalling responses.

\section{Methods}

\section{Database searches}

We conducted blastx and blastp searches in the NCBI nucleotide, protein and EST databases, the Gene Index Project (The Gene Index Databases-Dana Faber Cancer Institute; [54-56], Uniprot (The Uniprot Consortium, 2012), The P. abies genome v 1.0 [33] and Phytozome v9.1 [57] to collect our dataset. Our database search was performed in two steps: 1.) GPA1, AGB1, AGG1, AGG2 and AGG3 protein sequences (from $A$. thaliana) were 
used as the input data to retrieve the first set of sequences and 2.) The validated sequences of this first set were then used to repeat the database search to ensure high coverage of our dataset. The recovered nucleotide sequences were translated into amino acid sequences using the translate function (with standard genetic code) of the Sequence Manipulation Suite [58]. To verify the retrieved dataset we queried The Arabidopsis Information Resource (https://www.arabidopsis.org/) protein database and analysed the hit with highest similarity.

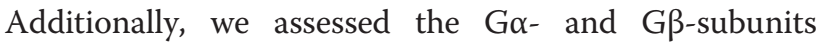
alignability with the $A$. thaliana sequences and searched for the conserved domains described by Trusov et al. [22] in the possible Gy-subunits.

The retrieved sequences were combined with identified dicot $\mathrm{G} \gamma$-subunits and the full-length $\mathrm{G} \alpha$-subunits of P. glauca and P. taeda from the verified dataset published in Urano et al. [9] (Additional file 1) for phylogenetic analyses. The G $\alpha$-subunit-like and G $\beta$-subunit-like datasets include sequences from species in the Brassicaceae, Fabaceae and Pinaceae and P. patens G $\beta$-subunitlike sequence. We created a $\mathrm{G} \gamma$-subunit-like dataset with isequences from the Brassicaceae, Fabaceae, Pinaceae and P. patens.

We observed unusual valine-rich C-termini in the Medicago truncatula $\mathrm{G} \gamma$-subunit C-type-like in our datasets. Analyses of the genomic sequences showed frame shifts in the predicted exon-border (Phytozome v9.1 [57]) in all three sequences: Medtr8g021170.1 showed a one-base frame shift in its last exon, Medtr2g042200.1 had a twobases frame shift in the second to last exon by of Medtr2g042200.1 and in Medtr4g125190.1 a five-bases elongation in the $5^{\prime}$ end of the second to last exon was corrected to gain cysteine-rich $\mathrm{C}$-termini. For further information on the alignments see Additional files 4, 5 and 6.

\section{Amplification of $P$. abies G-protein sequences}

We cloned the full-length heterotrimeric G-protein subunit coding sequences from $P$. abies. The primers were designed based on the retrieved ESTs and nucleotide sequences from three Pinaceae species: $P$. sitchensis, $P$. glauca and $P$. abies. Primer sequences were listed in Additional file 8.

The PaGPA1 gene appeared to be split into two different predicted transcripts, comp92545_c0_seq1 and comp92545_c1_seq1 in the $P$. abies 1.0 genome database. Amplification of the predicted $1173 \mathrm{bp}$ full-length transcript was performed in a PCR reaction consisting of 1x Dream-Taq green buffer, $0.25 \mu \mathrm{M}$ of each of the primers, $0.2 \mathrm{mM}$ dNTPs, 6.25U Dream-Taq Polymerase (Fermentas) and $1 \mu \mathrm{l}$ of $P$. abies cDNA. Initial denaturation was at $95{ }^{\circ} \mathrm{C}$ for $5 \mathrm{~min}$, followed by 35 cycles of: $15 \mathrm{~s}$ at $95^{\circ} \mathrm{C}, 20 \mathrm{~s}$ at $58^{\circ} \mathrm{C}$ and $120 \mathrm{~s}$ at $72{ }^{\circ} \mathrm{C}$ and a final elongation step of $3 \mathrm{~min}$ at $72{ }^{\circ} \mathrm{C}$.
The PaHGB1 sequence was amplified from $P$. abies cDNA via a two-step PCR using the Advantage 2 DNA polymerase mix (Clontech Laboratories, Inc.), 1:50 diluted PCR product of the first reaction was used as template for the second reaction to increase the product amount.

Gy-subunit-like sequences PaGG1, PaGG2, PaGG3 and PaGG4 were amplified from 3 ' - and $5^{\prime}$-SMARTer $^{\mathrm{mm}}$ RACE cDNA (Clontech Laboratories, Inc.) libraries of $P$. abies infected with $H$. parviporum, according to the manual's instructions in a two-step PCR approach (PaGG1, PaGG2 and $P a G G 3)$ and a nested PCR approach (PaGG4).

The PCR products of PaGPA1, PaHGB1, PaGG2 and PaGG3 were extracted from agarose gels with the Gen$J \mathrm{JT}^{\mathrm{Tm}}$ Gel Extraction kit according to manual, while the PCR products of PaGG1 and PaGG4 were directly purified with the GenJet ${ }^{\mathrm{tm}}$ PCR-purification kit. The purified PCR products were cloned using $\mathrm{TOPO}^{\circ} \mathrm{TA}$ Cloning (Life Technologies) according to instructions and plasmids were sequenced at Macrogen (Amsterdam, Netherlands). Good quality sequences were translated into amino acid sequences using the translate function with standard genetic code of the Sequence manipulation suite [58]. We verified all amino acid sequences as heterotrimeric Gprotein complex components in TAIR and NCBI as described previously. Secondary structures of the amino acid sequences were predicted using the PreSSAPro software (http://bioinformatica.isa.cnr.it/PRESSAPRO/).

\section{Phylogenetic analyses}

Phylogenetic relationships of the different subunit types of the heterotrimeric G-protein were analysed with MEGA 5.0 [59]. Phylogenies were constructed for all datasets with the Neighbor-joining algorithm, 1000 bootstrap repetitions, p-distance estimations as a statistical model, uniform substitution rates and a partial sequence cutoff value of $95 \%$. G $\alpha$-subunit-like and G $\beta$-subunitlike sequences were aligned using CLUSTALW with default options, $\mathrm{G} \gamma$-subunit sequences were aligned manually due to their high sequence variability.

\section{Amino acid sequence characteristics of $\mathrm{G} \gamma$ repertoire in Picea abies}

Molecular weight predictions and sequence identity and similarity analyses were performed with the Protein molecular weight function and ident and sim functions of the Sequence manipulation suite [58]. Sequence similarity predictions were based on the alignment in Fig. 1 and similar amino acids were grouped according to the suggestions in MEGA 5.0 [59], for better comparison of the data.

\section{Conservation of heterotrimeric G-proteins}

We estimated sequence divergence as mean amino acid mismatches /sequence length of pairwise comparisonsfor 
Go-subunit-like sequences and for A- and C-type-like $\mathrm{G} \gamma$ subunits. Every gap was considered a mismatch. In comparisons including at least one incomplete sequence, only the region covered by both sequences was considered. To gain a better understanding about G-protein evolution in Pinaceae we analysed sequence divergence within the following phylogenetic clusters: i) Fabaceae-Brassicaceae, ii) Fabaceae, iii) Brassicaceae, iv) Pinaceae, v) Picea and vi) Pinus, if the cluster contained more than three different species. The AGG1-like cluster of the Fabaceae was omitted, because the incompleteness of the Vigna unguiculata sequence FF393368.1 biased the results due to the high sequence variability. The statistical differences between the clusters were tested using a one-way ANOVA followed by Tukey post-hoc test.

\section{Biological material}

H. annosum s.s. isolate Sä16-4 [60] was cultivated on Hagem medium [60] plates at $25^{\circ} \mathrm{C}$ in the dark until the plates were covered with mycelia. Conidia were isolated from the surface with autoclaved water and a Drigalski spatula. The suspension was filtered through glass wool. Conidia concentration was determined using a hemocytometer (Bürker, Scherf Präzision).

Seeds of P. abies (S09/120) were surface sterilized with $33 \%$ hydrogen peroxide, one drop Tween 20 was added and seeds were gently rotated in the sterilization solution for 15 min followed by 6 washes with autoclaved water. Seeds were covered in water and imbibed over night at $4{ }^{\circ} \mathrm{C}$. The seeds were allowed to germinate on water agar and then transferred onto slanted 1/4 SchenkHildebrandt medium (pH 5.6; Duchefa Biochemie) with $0.35 \%$ gelrite (Duchefa) until developing the first true needles. Seedlings were incubated in a vertical position at $22{ }^{\circ} \mathrm{C}$ under long day conditions.

\section{Gene expression experimental set-up}

$P$. abies seedlings used in the expression studies were i) transferred to Schenk-Hildebrandt medium with $10 \mu \mathrm{M}$ ABA (stock solution $100 \mathrm{mM} \mathrm{ABA}$ in $100 \% \mathrm{EtOH}$; Sigma Aldrich), ii) wounded on their hypocotyl with a needle iii) treated with $3 \mathrm{ml}$ of a $H$. annosum s.s. isolate Sä16-4 conidiospore suspension at $1.5 \times 10^{6} \pm 31 \times 10^{5}$ (SE) spores $/ \mathrm{ml}$ and iv) treated with MeJA (Sigma Aldrich). Seedlings treated with MeJA were incubated in a closed chromatography chamber with $75 \mu \mathrm{l} 10 \% \mathrm{MeJA}$ per 11 chamber volume. Samples were taken at 0, 4, 24 and $72 \mathrm{~h}$ post treatment. Root and cotyledons were collected separately, frozen with liquid nitrogen and stored at $-70{ }^{\circ} \mathrm{C}$ until further use. Each treatment and control included three biological replicates with five seedlings per replicate.

Expression analyses in $P$. abies bark were done on branches of four years old plants, from the full-sib family
S21H982005 originating from the Swedish breeding programme, inoculated with $P$. gigantea (Rotstop S), $H$. parviporum (Rb175) or wounding as described in Arnerup et al. [47]. Samples from the wounding/inoculation site $(0-0.5 \mathrm{~cm})$ and a distal location $(1.5-2.5 \mathrm{~cm})$ taken $72 \mathrm{hpi}$ were analysed. Three biological replicates per treatment were used.

\section{Quantitative PCR}

Total RNA extraction was done essentially according to the protocol by Chang et al. [61]. Samples were DNase treated with DNase1 (Sigma Aldrich, USA) according to the manufacturer's instructions and RNA concentration was determined with the NanoDrop (Spectrophotometer ND 1000, Saven Werner). 300 ng of total RNA was reverse transcribed to cDNA with the iScript ${ }^{\text {ti }}$ cDNA Synthesis Kit (BIO-RAD, Sundbyberg, Sweden) according to the manufacturer's instructions .

Quantitative PCR was performed with the SsoFast ${ }^{\mathrm{m}}$ EvaGreen ${ }^{\circ}$ Supermix (BIO-RAD) according to the instructions in the manual, using $0.3 \mu \mathrm{M}$ of each primer. The qPCR were carried out in an iQ5 ${ }^{\mathrm{Tm}}$ Multicolor RealTime PCR Detection System thermo cycler (Bio-Rad) using a program with a $30 \mathrm{~s}$ initial denaturation step at $95{ }^{\circ} \mathrm{C}$, followed by 40 cycles of $5 \mathrm{~s}$ denaturation at $95{ }^{\circ} \mathrm{C}$ and $10 \mathrm{~s}$ at $60{ }^{\circ} \mathrm{C}$. Melt curve analyses were used to validate the amplicon. Relative expression (fold change) was calculated using the $2^{-\Delta \Delta C T}$ method [62]. One-way ANOVA with the Tukey post-hoc test or the Mann-Whitney $U$ test in the GraphPad Prism 5.0 statistical package (GraphPad Inc.) was used to test for statistical differences in expression.

Yeast two hybrid assay among conifer G-protein subunits PaGPA1, PaHGB1, PaGG1, PaGG2, PaGG3 and PaGG4 cDNA sequences were amplified with Attb primers (Additional file 8) in a PCR reaction consisting of $1 x$ Dream-Taq green buffer, $0.25 \mu \mathrm{M}$ of each of the primers, $0.2 \mathrm{mM}$ dNTPs, 6.25U Dream-Taq Polymerase (Fermentas) and $1 \mu \mathrm{l}$ of $P$. abies cDNA. Initial denaturation was at $95{ }^{\circ} \mathrm{C}$ for $5 \mathrm{~min}$, followed by 35 cycles of: $15 \mathrm{~s}$ at $95{ }^{\circ} \mathrm{C}, 20 \mathrm{~s}$ at $58{ }^{\circ} \mathrm{C}$ and $120 \mathrm{~s}$ at $72{ }^{\circ} \mathrm{C}$ and a final elongation step of $3 \mathrm{~min}$ at $72{ }^{\circ} \mathrm{C}$. PCR products were directly purified with the GenJet ${ }^{\mathrm{m}}$ PCR-purification kit. Purified PCR products were then cloned into $\mathrm{pDONR}^{\mathrm{m \omega}} /$ Zeo vectors by Gateway ${ }^{\circ} \mathrm{BP}$ recombination. TOP10 competent cells were transformed and colonies were selected in LB medium with $50 \mu \mathrm{g} / \mathrm{mL}$ zeocin. Colonies were grown overnight on liquid LB medium with $50 \mu \mathrm{g} / \mathrm{mL}$ zeocin and plasmids were isolated using GenJet ${ }^{\mathrm{m}}$ plasmid minikit and plasmids were verified by PCR using the Attb primers for the different G-protein subunits.

PaGPA1, PaHGB1, PaGG1, PaGG2, PaGG3 and PaGG4 were transferred from pDONR/Zeo entry vectors 
into pDest-DB and pDest-AD-CYH2 vectors by Gateway ${ }^{\circ}$ LR recombination to generate Gal4 DNA binding domain (DB) and Gal4 activation domain (AD) hybrid proteins, respectively. The LR reaction was used to transform into TOP10 competent cells and colonies were selected on LB plates with $100 \mu \mathrm{g} / \mathrm{mL}$ ampicillin. Colonies were grown overnight on liquid LB medium with $100 \mu \mathrm{g} / \mathrm{mL}$ ampicillin and plasmids were isolated using GenJet ${ }^{\mathrm{tw}}$ plasmid minikit and plasmids were sequenced at Macrogen (Amsterdam, Netherlands) for confirmation.

The resulted $\mathrm{DB}$ and $\mathrm{AD}$ plasmids were individually transformed into haploid yeast (S. cerevisiae) strains Y8930 (MAT $\alpha$ ) and Y8800 (MATa) to create baits and preys, respectively as described [63]. Briefly, Y8930 and Y8800 strains were grown in liquid YEPD overnight. A 0.1 OD culture was prepared the following morning. Once the OD reached 0.4-0.6, the cells were harvested and prepared for transformation. The baits and preys were selected on Difco ${ }^{\text {Tw }}$ yeast nitrogen base (YNB) with leucine dropout $(-\mathrm{L})$ and tryptophan dropout $(-\mathrm{T})$ selective media respectively. The haploid bait and prey yeast strains were pairwise mated $\mathrm{o} / \mathrm{n}$ in YEPD. The diploid yeast cells were selected onto YNB -LT selective liquid media, and subsequently spotted onto YNB -LTH as well as - $\mathrm{LH}$ containing cycloheximide ( $\mathrm{CHX}$ ) selective media. In addition we also determined the strength of protein-protein interaction by supplementing -LTH and -LH with 3-Amino- 1, 2, 4-trizole (3AT), a competitive inhibitor of histidine biosynthesis. Yeast growth on -LTH but not on - $\mathrm{LH}$ containing CHX media were scored as positive interactions. Yeast growth found on both $-\mathrm{LTH}$ and $-\mathrm{LH}$ containing $\mathrm{CHX}$ were due to de novo autoactivation and hence removed from the data set.

\section{Availability of supporting data}

The data sets supporting the results of this article are included within the article and its additional files.

\section{Additional files}

\section{Additional file 1: Accession numbers for the Ga-, $\mathrm{G} \beta$ - and} Gy-subunits sequences found in the plant kingdom. Sequences have been either cloned or retrieved from the Gene Index Project (The Gene Index Databases-Dana Faber Cancer Institute; Lee et al., [54]; Pertea et al., [55]; Quackenbush et al., [56] ; Tsai et al., [64]), NCBI EST/Nucleotide/Protein, Phytozome v9.1 (Goodstein et al., [57]) or Uniprot [65]; underlined sequences were used for primer design. (DOCX $18 \mathrm{~kb}$ )

Additional file 2: Predictions of alpha-helices in short Gy-subunits PaGG1, PaGG2, GG1 and GG2. The GGL domain (pfam00631) is underlined. The PreSSAPro software (http://bioinformatica.isa.cnr.it/ PRESSAPRO/) was used to predict the formation of a-helices based on amino acid propensities, residues likely to form a-helices are shown in bold font and are boxed, residues shared between three or more proteins are shaded and asterisks indicate conserved amino acids. (PDF $10 \mathrm{~kb})$
Additional file 3: Alignment of the Ga-subunit protein sequences used for the Ga-phylogeny; the asteriks indicates sequences obtained from Urano et al. ([9, 10]). (XLS $103 \mathrm{~kb})$

Additional file 4: Alignment the $\mathrm{G} \beta$-subunit protein sequences used for the $G \beta$-phylogeny; the asteriks indicates sequences where the accession number corresponds to a nucleotide sequence, instead of an amino acid sequence. Nucleotide sequences have been translated using the translate function from the Sequence Manipulation Suite [58]. (XLS $105 \mathrm{~kb})$

Additional file 5: Phylogeny of Ga- and G $\beta$-subunits of the plant kingdom. The figure shows neighbor-joining trees of full-length sequence alignments of the Ga- (a) and G $\beta$-subunits. (b) including sequences from species of the Brassicaceae (blue), Fabaceae (orange) and Pinaceae (purple) and the moss Physcomitrella patens (green, root). Bootstrap support over 65 is indicated at the nodes. (PDF $502 \mathrm{~kb}$ )

Additional file 6: Alignment of Gy-subunit sequences. (PDF $8038 \mathrm{~kb}$ ) Additional file 7: Relative expression values of PaGG1, PaGG3, PaHGB1 and PaGPA1 in cotyledons and roots of $P$. abies treated with abscisic acid, methyl jasmonate, wounding at 4 and $24 \mathrm{~h}$ post treatment compared to $0 \mathrm{~h}$. (XLSX $12 \mathrm{~kb}$ )

Additional file 8: Primer sequences for full-length amplification of the Ga-, G $\beta$ - and GY-subunits cloning of the sequences and qPCR. (DOCX $17 \mathrm{~kb}$ )

Competing interests

The authors declare that they have no competing interests.

\section{Authors' contributions}

SdV and ME conceived the study and designed the experiments. SdV and MNG performed the experiments. MK and SdV performed the gene family evolution analyses. MNG, PBB and SMM designed and performed the $\mathrm{Y} 2 \mathrm{H}$ study. SdV analysed the data. SdV and ME drafted the manuscript. All authors read and approved the final manuscript.

\section{Acknowledgements}

We would like to thank Dr. Katarina Ihrmark for skillfull technical help in the laboratory and Dr. Mukesh Dubey for valuable discussions on the manuscript. Financial support was received from the Swedish Foundation for Strategic Research (SSF), grant number R8b08-0011, and by the Swedish Research Council FORMAS, grant nr 2012-1276. M. Shahid Mukhtar was supported through funds from the Department of Biology, University of Alabama at Birmingham. The funders had no role in study design, data collection and analysis, decision to publish, or preparation of the manuscript.

\section{Author details}

${ }^{1}$ Department of Forest Mycology and Plant Pathology, Uppsala Biocenter, Swedish University of Agricultural Sciences, Uppsala, Sweden. ${ }^{2}$ Institute of Population Genetics, Heinrich Heine-University, Düsseldorf, Germany. ${ }^{3}$ Department of Biology, The University of Alabama at Birmingham, Birmingham, AL, USA.

Received: 21 September 2015 Accepted: 3 December 2015 Published online: 12 December 2015

\section{References}

1. Delgado-Cerezo M, Sanchez-Rodriguez C, Escudero V, Miedes E, Virginia Fernandez $\mathrm{P}$, Jorda $\mathrm{L}$, et al. Arabidopsis heterotrimeric G-protein regulates cell wall defense and resistance to necrotrophic fungi. Mol Plant. 2012;5(1): 98-114.

2. Klopffleisch K, Nguyen P, Augustin K, Bayne RS, Booker KS, Botella JR, et al. Arabidopsis $\mathrm{G}$-protein interactome reveals connections to cell wall carbohydrates and morphogenesis. Molecular Systems Biology. 2011;7.

3. Li S, Liu Y, Zheng L, Chen L, Li N, Corke F, et al. The plant-specific G protein y subunit AGG3 influences organ size and shape in Arabidopsis thaliana. New Phytol. 2012;194(3):690-703.

4. Millner PA. Heterotrimeric G-proteins in plant cell signaling. New Phytol. 2001;151(1):165-74. 
5. Okamoto H, Goebel C, Capper RG, Saunders N, Feussner I, Knight MR. The alpha-subunit of the heterotrimeric G-protein affects jasmonate responses in Arabidopsis thaliana. J Exp Bot. 2009;60(7):1991-2003.

6. Trusov Y, Rookes JE, Chakravorty D, Armour D, Schenk PM, Botella JR. Heterotrimeric $\mathrm{G}$ proteins facilitate Arabidopsis resistance to necrotrophic pathogens and are involved in jasmonate signaling. Plant Physiol. 2006; 140(1):210-20

7. Trusov Y, Sewelam N, Rookes JE, Kunkel M, Nowak E, Schenk PM, et al. Heterotrimeric $\mathrm{G}$ proteins-mediated resistance to necrotrophic pathogens includes mechanisms independent of salicylic acid-, jasmonic acid/ethylene- and abscisic acid-mediated defense signaling. Plant J. 2009;58(1):69-81.

8. Ullah H, Chen JG, Young JC, Im KH, Sussman MR, Jones AM. Modulation of cell proliferation by heterotrimeric $\mathrm{G}$ protein in Arabidopsis. Science. 2001; 292(5524):2066-9.

9. Urano D, Jones JC, Wang H, Matthews M, Bradford W, Bennetzen JL, et al. G protein activation without a GEF in the plant kingdom. Plos Genetics. 2012; 8(6):e1002756.

10. Urano D, Nguyen P, Jones JC, Yang J, Huang J, Grigston J, et al. Endocytosis of the seven-transmembrane RGS1 protein activates G-protein-coupled signalling in Arabidopsis. Nat Cell Biol. 2012;14(10):1079-+.

11. Wang $X Q$, Ullah $H$, Jones $A M$, Assmann SM. G protein regulation of ion channels and abscisic acid signaling in Arabidopsis guard cells. Science. 2001;292(5524):2070-2.

12. Urano D, Chen JG, Botella JR, Jones AM. Heterotrimeric G protein signalling in the plant kingdom. Open Biol. 2013;3(3):120186.

13. Johnston CA, Taylor JP, Gao Y, Kimple AJ, Grigston JC, Chen J-G, et al. GTPase acceleration as the rate-limiting step in Arabidopsis $\mathrm{G}$ protein-coupled sugar signaling. Proc Natl Acad Sci U S A. 2007;104(44):17317-22.

14. Jones JC, Duffy JW, Machius M, Temple BRS, Dohlman HG, Jones AM. The crystal structure of a self-activating $G$ protein alpha subunit reveals its distinct mechanism of signal initiation. Science Signaling. 2011;4(159):ra8.

15. Temple BRS, Jones AM. The plant heterotrimeric G-protein complex. Annu Rev Plant Biol. 2007:58:249-66.

16. Urano D, Jones AM. Heterotrimeric G protein-coupled signaling in plants. Annu Rev Plant Biol. 2014;65:365-84.

17. Pandey S, Wang R-S, Wilson L, Li S, Zhao Z, Gookin TE, et al. Boolean modeling of transcriptome data reveals novel modes of heterotrimeric G-protein action. Molecular Systems Biology. 2010;6

18. Thung L, Chakravorty D, Trusov Y, Jones AM, Botella JR. Signaling specificity provided by the Arabidopsis thaliana heterotrimeric G-protein gamma subunits AGG1 and AGG2 is partially but not exclusively provided through transcriptional regulation. Plos One. 2013, 8(3):e58503

19. Lochrie MA, Simon MI. G-protein multiplicity in eukaryotic signal transduction systems. Biochemistry. 1988;27(14):4957-65.

20. Strathmann M, Wilkie TM, Simon MI. Diversity of the G-protein family -sequences from 5 additional alpha-subunits in the mouse. Proc Natl Acad Sci U S A. 1989;86(19):7407-9.

21. Trusov Y, Rookes JE, Tilbrook K, Chakravorty D, Mason MG, Anderson D, et al. Heterotrimeric $\mathrm{G}$ protein gamma subunits provide functional selectivity in $\mathrm{G}$ beta gamma dimer signaling in Arabidopsis. Plant Cell. 2007;19(4):1235-50.

22. Trusov Y, Chakravorty D, Botella JR. Diversity of heterotrimeric G-protein gamma subunits in plants. BMC research notes. 2012;5:608.

23. Hackenberg D, Sakayama H, Nishiyama T, Pandey S. Characterization of the heterotrimeric G-protein complex and its regulator from the green alga Chara braunii expands the evolutionary breadth of plant G-protein signaling. Plant Physiol. 2013;163(4):1510-7.

24. Pires ND, Dolan L. Morphological evolution in land plants: new designs with old genes. Philosophical Transactions of the Royal Society B-Biological Sciences. 2012;367(1588):508-18.

25. Izawa Y, Takayanagi Y, Inaba N, Abe Y, Minami M, Fujisawa Y, et al. Function and expression pattern of the alpha subunit of the heterotrimeric $G$ protein in rice. Plant Cell Physiol. 2010;51(2):271-81.

26. Gao Y, Li T, Liu Y, Ren C, Zhao Y, Wang M. Isolation and characterization of gene encoding $G$ protein alpha subunit protein responsive to plant hormones and abiotic stresses in Brassica napus. Mol Biol Rep. 2010;37(8):3957-65.

27. Gao Y, Li T, Zhao Y, Ren C, Zhang Y, Wang M. Isolation and characterization of a $G$ protein gamma subunit gene responsive to plant hormones and abiotic stresses in Brassica napus L. Acta Physiologiae Plantarum. 2011;33(2):391-9.

28. Bisht NC, Jez JM, Pandey S. An elaborate heterotrimeric G-protein family from soybean expands the diversity of plant G-protein networks. New Phytol. 2011; 190(1):35-48.
29. Suharsono U, Fujisawa Y, Kawasaki T, Iwasaki Y, Satoh H, Shimamoto K. The heterotrimeric $\mathrm{G}$ protein alpha subunit acts upstream of the small GTPase Rac in disease resistance of rice. Proc Natl Acad Sci U S A. 2002;99(20):13307-12.

30. Liu J, Ding P, Sun T, Nitta Y, Dong O, Huang X, et al. Heterotrimeric G proteins serve as a converging point in plant defense signaling activated by multiple receptor-like kinases. Plant Physiol. 2013;161(4):2146-58.

31. Zhang H, Wang M, Wang W, Li D, Huang Q, Wang Y, et al. Silencing of G proteins uncovers diversified plant responses when challenged by three elicitors in Nicotiana benthamiana. Plant, Cell Environ. 2012;35(1):72-85.

32. Lee S, Rojas CM, Ishiga Y, Pandey S, Mysore KS. Arabidopsis heterotrimeric G-proteins play a critical role in host and nonhost resistance against Pseudomonas syringae pathogens. Plos One. 2013;8(12):e82445.

33. Nystedt B, Street NR, Wetterbom A, Zuccolo A, Lin Y-C, Scofield DG, et al. The Norway spruce genome sequence and conifer genome evolution. Nature. 2013;497(7451):579-84.

34. Korhonen K, Stenlid J. Biology of Heterobasidion annosum. In: Woodward S, Stenlid J, Karjalainen R, Hüttermann A, editors. In heterobasidion annosum: biology, ecology, impact and control. Wallingford, Oxon, UK: CAB International; 1998. p. 43-70.

35. Arnerup J, Lind M, Olson A, Stenlid J, Elfstrand M. The pathogenic white-rot fungus Heterobasidion parviporum triggers non-specific defence responses in the bark of Norway spruce. Tree Physiology. 2011;31(11):1262-72.

36. Danielsson M, Lunden K, Elfstrand M, Hu J, Zhao T, Arnerup J, et al. Chemical and transcriptional responses of Norway spruce genotypes with different susceptibility to Heterobasidion spp. infection. BMC Plant Biology. 2011;11(154):154.

37. Yaqoob N, Yakovlev IA, Krokene P, Kvaalen H, Solheim H, Fossdal CG. Defence-related gene expression in bark and sapwood of Norway spruce in response to Heterobasidion parviporum and methyl jasmonate. Physiological and Molecular Plant Pathology. 2012;77(1):10-6.

38. Dalman K, Olson A, Stenlid J. Evolutionary history of the conifer root rot fungus Heterobasidion annosum sensu lato. Molecular Ecology. 2010;19(22): 4979-93.

39. Snow BE, Krumins AM, Brothers GM, Lee SF, Wall MA, Chung S, et al. A G protein gamma subunit-like domain shared between RGS11 and other RGS proteins specifies binding to $\mathrm{G}$ (beta 5) subunits. Proc Natl Acad Sci U S A. 1998;95(22):13307-12.

40. Wang $X Q$, Tank DC, Sang T. Phylogeny and divergence times in Pinaceae: Evidence from three genomes. Mol Biol Evol. 2000;17(5):773-81.

41. Willyard A, Syring J, Gernandt DS, Liston A, Cronn R. Fossil calibration of molecular divergence infers a moderate mutation rate and recent radiations for pinus. Mol Biol Evol. 2007;24(1):90-101.

42. Wall MA, Coleman DE, Lee E, Iniguezlluhi JA, Posner BA, Gilman AG, et al. The structure of the $\mathrm{G}$-protein heterotrimer $\mathrm{G}(\mathrm{l}$-alpha) beta (1) gamma (2). Cell. 1995;83(6):1047-58.

43. Cook LA, Schey KL, Cleator JH, Wilcox MD, Dingus J, Hildebrandt JD. Identification of a region in $\mathrm{G}$ protein gamma subunits conserved across species but hypervariable among subunit isoforms. Protein Sci. 2001;10(12):2548-55.

44. Rahmatullah M, Robishaw JD. Direct interaction of the alpha-subunit and gamma subunit of the G-proteins- purification and analysis by limited proteolysis. J Biol Chem. 1994;269(5):3574-80.

45. Rahmatullah M, Ginnan R, Robishaw JD. Specificity of G-protein alpha-gamma subunit interactions-N-terminal 15 amino-acids of gamma specifies interaction with alpha subunit. J Biol Chem. 1995;270(7):2946-51.

46. Wikstrom N, Savolainen V, Chase MW. Evolution of the angiosperms: calibrating the family tree. Proceedings of the Royal Society B-Biological Sciences. 2001;268(1482):2211-20.

47. Arnerup J, Nemesio-Gorriz M, Lundén K, Asiegbu FO, Stenlid J, Elfstrand M. The primary module in Norway spruce defence signalling against $H$. annosum s.l. seems to be jasmonate-mediated signalling without antagonism of salicylate-mediated signalling. Planta. 2013;237(4):1037-45.

48. Cherfils J, Chabre M. Activation of $\mathrm{G}$-protein $\mathrm{G}$ alpha subunits by receptors through $\mathrm{G}$ alpha- $\mathrm{G}$ beta and $\mathrm{G}$ alpha- $\mathrm{G}$ gamma interactions. Trends Biochem Sci. 2003;28(1):13-7

49. Buschiazzo E, Ritland C, Bohlmann J, Ritland K. Slow but not low: genomic comparisons reveal slower evolutionary rate and higher $\mathrm{dN} / \mathrm{dS}$ in conifers compared to angiosperms. Bmc Evolutionary Biology. 2012;12.

50. Boller T, Felix G. A renaissance of elicitors: perception of microbe-associated molecular patterns and danger signals by pattern-recognition receptors. Annu Rev Plant Biol. 2009;60:379-406. 
51. Schwacke R, Hager A. Fungal elicitors induce a transient release of active oxygen species from cultured spruce cells that depend on $\mathrm{Ca} 2+$ and protein-kinase activity. Planta. 1992;187(1):136-41.

52. Hebe G, Hager A, Salzer P. Initial signalling processes induced by elicitors of ectomycorrhiza-forming fungi in spruce cells can also be triggered by G-protein-activating mastoparan and protein phosphatase-inhibiting cantharidin. Planta. 1999;207(3):418-25.

53. Miles GP, Samuel MA, Jones AM, Ellis BE. Mastoparan rapidly activates plant MAP kinase signaling independent of heterotrimeric G proteins. Plant Physiol. 2004;134(4):1332-6.

54. Lee Y, Sultana R, Pertea G, Cho J, Karamycheva S, Tsai J, et al. Cross-referencing eukaryotic genomes: TIGR orthologous gene alignments (TOGA). Genome Res. 2002;12(3):493-502.

55. Pertea G, Huang XQ, Liang F, Antonescu V, Sultana R, Karamycheva S, et al. TIGR Gene Indices clustering tools (TGICL): a software system for fast clustering of large EST datasets. Bioinformatics. 2003;19(5):651-2.

56. Quackenbush J, Liang F, Holt I, Pertea G, Upton J. The TIGR Gene Indices: reconstruction and representation of expressed gene sequences. Nucleic Acids Res. 2000;28(1):141-5.

57. Goodstein DM, Shu S, Howson R, Neupane R, Hayes RD, Fazo J, et al. Phytozome: a comparative platform for green plant genomics. Nucleic Acids Res. 2012:40(D1):D1178-86.

58. Stothard P. The sequence manipulation suite: JavaScript programs for analyzing and formatting protein and DNA sequences. Biotechniques. 2000; 28(6):1102-+.

59. Tamura K, Peterson D, Peterson N, Stecher G, Nei M, Kumar S. MEGA5: molecular evolutionary genetics analysis using maximum likelihood, evolutionary distance, and maximum parsimony methods. Mol Biol Evol. 2011;28(10):2731-9.

60. Stenlid J. Population structure of Heterobasidion annosum as determined by somatic incompatibility, sexual incompatibility and isoenzyme patterns. Can J Bot. 1985;63(12):2268-73.

61. Chang S, Puryear J, Cairney J. A simple and efficient method for extracting RNA from pine trees. Plant Molecular Biology Reporter. 1993;11(2):113-6.

62. Livak KJ, Schmittgen TD. Analysis of relative gene expression data using real-time quantitative PCR and the 2(T)(-Delta Delta C) method. Methods. 2001;25(4):402-8.

63. Mukhtar MS, Carvunis AR, Dreze M, Epple P, Steinbrenner J, Moore J, et al. Independently evolved virulence effectors converge onto hubs in a plant immune system network. Science. 2011;333(6042):596-601.

64. Tsai J, Sultana R, Lee Y, Pertea G, Karamycheva S, Antonescu V, et al. RESOURCERER: a database for annotating and linking microarray resources within and across species. Genome Biology 2001, 2(11).

65. Consortium TU. UniProt: a hub for protein information. Nucleic Acids Research. 2015;43(D1):D204-D212

\section{Submit your next manuscript to BioMed Central and we will help you at every step:}

- We accept pre-submission inquiries

- Our selector tool helps you to find the most relevant journal

- We provide round the clock customer support

- Convenient online submission

- Thorough peer review

- Inclusion in PubMed and all major indexing services

- Maximum visibility for your research

Submit your manuscript at www.biomedcentral.com/submit 